University of Nebraska - Lincoln

DigitalCommons@University of Nebraska - Lincoln

\title{
The Sticky Card: Device for Studying the Distribution of Adult House Fly (Diptera: Muscidae) Populations in Closed Poultry Houses
}

Jerome Hogsette

USDA-ARS, Jerry.Hogsette@ars.usda.gov

Roger Jacobs

USDA-ARS

Richard Miller

USDA-ARS

Follow this and additional works at: https://digitalcommons.unl.edu/usdaarsfacpub

Part of the Agricultural Science Commons

Hogsette, Jerome; Jacobs, Roger; and Miller, Richard, "The Sticky Card: Device for Studying the Distribution of Adult House Fly (Diptera: Muscidae) Populations in Closed Poultry Houses" (1993). Publications from USDA-ARS / UNL Faculty. 1006.

https://digitalcommons.unl.edu/usdaarsfacpub/1006

This Article is brought to you for free and open access by the U.S. Department of Agriculture: Agricultural Research Service, Lincoln, Nebraska at DigitalCommons@University of Nebraska - Lincoln. It has been accepted for inclusion in Publications from USDA-ARS / UNL Faculty by an authorized administrator of DigitalCommons@University of Nebraska - Lincoln. 


\title{
The Sticky Card: Device for Studying the Distribution of Adult House Fly (Diptera: Muscidae) Populations in Closed Poultry Houses
}

\author{
JEROME A. HOGSETTE, ROGER D. JACOBS, ${ }^{1}$ AND RICHARD W. MILLER ${ }^{2}$ \\ USDA-ARS, Medical and Veterinary Entomology Research Laboratory, P.O. Box 14565, \\ Gainesville, FL 32604
}

\begin{abstract}
J. Econ. Entomol. 86(2): 450-454 (1993)
ABSTRACT A commercially available sticky card was evaluated for use in adult fly distribution studies in large, closed poultry houses in Florida and Maryland. Results showed that house flies, Musca domestica L., preferred the interior parts of the houses, away from the walls. No vertical stratification was observed in Maryland, but flies in Florida stayed closer to the floor. In-house dispersal studies using fluorescent dust showed that flies would move $\approx 50 \mathrm{~m}$, or one-third the length of the house, in $<24 \mathrm{~h}$. Specimens of Hydrotaea aenescens (Wiedemann) (formerly Ophyra aenescens) were recovered in both states.
\end{abstract}

KEY WORDS Musca domestica, sticky card, population dynamics

MANY METHODS have been used to sample adult house flies, Musca domestica L., on poultry farms for the calculation of population density estimates. Noteworthy examples include the modified Scudder grid (Morgan et al. 1981), baited jug-traps, spot cards, and sticky ribbons (Axtell 1970; Rutz \& Axtell 1979, 1981; Burg \& Axtell 1984; Lysyk \& Axtell 1985) and the moving sticky tape (Turner \& Ruszler 1989). In contrast, only one study using ground-level baits has been done specifically to study the distribution of adult house fly populations; this was done in open California-style poultry houses (Wilson \& Mulla 1975). Fly distribution studies in closed, environmentally controlled poultry houses cannot be found in the literature.

Fly control problems in environmentally controlled poultry houses are compounded by the house size (average length $\approx 152 \mathrm{~m}$ ), resident bird population $(60,000-144,000$ per house), and daily rate of wet manure production $(11,300 \mathrm{~kg}$ per day for a 100,000-bird house) (Hogsette 1992). Because evaporative cooling systems are used in many Florida poultry houses to reduce ambient air temperatures to within the comfort zone of the chicken, manure in these closed houses is usually in a liquid state; this situation

This article reports the results of research only. Mention of a proprietary product does not constitute an endorsement or a recommendation for its use by USDA.

1 Department of Poultry Science, Institute of Food and Ag. ricultural Sciences, University of Florida, Gainesville, FL 32611.

${ }^{2}$ Livestock Insects Laboratory, Livestock \& Poultry Sciences Institute, USDA-ARS, Beltsville, MD 20705. makes it difficult and risky to enter the manure pits and apply pesticides. Fly populations inside the closed houses are in an artificial environment separated completely from ambient conditions outside. Temperature and relative humidity are maintained within a narrow range. The manure pits are dark except when bird-level lighting systems are in operation. Only minute amounts of sunlight enter the houses. Better knowledge of adult fly distribution might lead to an improvement in fly-control techniques.

Here, we describe the use of a commercially available sticky card, a new method for studying fly distributions, particularly in large, closed poultry houses. This method enabled us to use the grid formed by the vertical support beams for card placement and map fly distribution at two vertical levels during predetermined time intervals. The sticky card was not compared with other fly sampling methods because no other method was considered suitable for our studies.

\section{Materials and Methods}

The sticky cards ( 76 by $127 \mathrm{~mm}$ ), supplied by Olson Products (Medina, $\mathrm{OH}$ ), were made from heavy card stock coated with an extruded adhesive and covered with a peelable backing. Cards were labeled in an adhesive-free margin $(\approx 13$ $\mathrm{mm}$ wide) along one of the short sides or on the reverse.

Trials were performed in the manure pit areas of closed high-rise poultry houses in Florida and Maryland. High-rise houses have two levels, with chickens caged on the top level and manure 
pits on the bottom (ground) level. In Florida, we used a 100,000 -bird (152 by $14 \mathrm{~m}$ ) pullet house near Zephyrhills (Pasco County). The manure pit area had a concrete floor with two central longitudinal rows of 53 metal support poles flanked by I beams on each wall (Fig. 1). Each lateral pair of support poles and subtending I beams (from wall to wall across the house) constituted a rank. The distance between ranks was $2.9 \mathrm{~m}$. The withinrank distances between I beams and the nearest support poles and between pairs of support poles were 3.5 and $5.9 \mathrm{~m}$, respectively. Exhaust fans were centered on the long sides of the house at bird and pit levels, with evaporative cooling pads across the short sides at bird level. Entry doors were on the west (short) side of the house. A berm of poultry feed $0.6 \mathrm{~m}$ high was situated parallel to the short side of the house between rows 2 and 3 to prevent the liquid manure from unexpectedly exiting through the west doors. Incandescent lights at bird level were activated automatically from 0700 to $1800 \mathrm{~h}$. During this period, light intensity in the pit was $<10$ luxes (i.e., enough light to read by, but with considerable difficulty). Working lights in the pit were off during the tests.

Twenty-seven ranks of cylindrical posts and I beams (half the length of the house plus the center rank) were used for sampling purposes. Bulldog (No. 2, $64 \mathrm{~mm}$, Hunt Manufacturing, Statesville, NC) clips were wired to metal posts at two levels ( 0.5 and $1.8 \mathrm{~m}$ above floor level) to accept cards. For use on I beams, one handle of each of two clips were joined together by a length of wire passed through the circular cutout. One clip was then fastened to the beam, leaving the other to accept the card.

In Maryland, we used a 60,000-bird (139 by 13 m) layer house near Westminister (Carroll County). The manure pit area also had a concrete floor with two longitudinal rows of 46 wooden support poles flanked by wooden beams on each wall. The distance between ranks was $3.1 \mathrm{~m}$. The within-rank distances between I beams and the nearest support poles and between pairs of support poles were 4.6 and $4.1 \mathrm{~m}$, respectively. Exhaust fans were located on the long sides of the house at pit level, but there were no evaporative cooling pads. Entry doors were on the northeast (short) side of the house. Incandescent lights at bird level were activated for $\approx 17 \mathrm{~h}$, and light intensity in the pit was $<10$ luxes. Working lights in the pit were off during the tests. Twenty-three ranks of wooden posts and beams (half the house) were used for sampling purposes. Bulldog clips were screwed into wooden posts at 0.3 and $1.8 \mathrm{~m}$ above floor level to accept cards. Wall beams were tied to a concrete block foundation wall $1.5 \mathrm{~m}$ high and did not extend to the floor. Therefore, bulldog clips were screwed into wall beams 1.5 and $1.8 \mathrm{~m}$ above floor level.
To initiate a test, a sticky card with peelable backing in place was affixed to each clip (216 and 184 cards per test in Florida and Maryland, respectively). The adhesive-free margin was slipped into the clip, leaving the peelable backing free for easy removal. The backing was then removed from the cards. No one entered the pit during the test period. When a test was terminated, cards were removed from the clips and stacked in paper bags ( 13 by 8 by $27 \mathrm{~cm}$ high) for later processing.

In Florida, test dates (all 1991) and card exposure periods were as follows: 1-2 May, 17300630 h; 2 May, 0700-1830 h; 22-23 May, 21002100 h; 23-24 May, 2100-0630 h; 4-5 June, 2200-0700 h; 18-19 June, 2200-2200 h. In Maryland, a 24-h test was performed on 5-6 August 1991, from 2100 to 2100 h. Except for tests that ended on 2 May, all in-house operations (e.g., card placement and removal) were performed essentially in complete darkness. Small flashlights turned on and off in rapid succession at long intervals were the only light source.

Adults of $M$. domestica and Hydrotaea aenescens (Wiedemann) (formerly Ophyra aenescens) captured on sticky cards in both states were counted and recorded. In Florida, sex ratio data were collected from cards in ranks $4,8,14$, 17 and 23 which were used in tests that terminated on 23 May, 5 June, and 19 June.

Marking techniques for in-house dispersal studies were evaluated in Florida while distribution tests were in progress. Before the start of tests that ended 23 and 24 May, signal green, corona magenta, and arc yellow fluorescent dust (Day-Glo Color, Cleveland, $\mathrm{OH}$ ) was applied with plunger-type dusters (Hogsette 1983) to each of eight blank (no adhesive) 76 by $127 \mathrm{~mm}$ cards outside the poultry house. Cards were then placed in clips in ranks 3 (signal green), 15 (corona magenta), and 25 (arc yellow) at both levels. Before the initiation of tests that ended 5 June and 19 June, corona-magenta and arc-yellow $\mathrm{flu}$ orescent dust was applied with plunger-type dusters directly onto flies resting between the upper and lower sticky cards on posts and I beams in rank 12 and in corresponding areas on posts and I beams in rank 29 (no cards on this rank), respectively, before paper backing was removed from cards. In the laboratory, all sticky cards from these tests were scanned under longwave ultraviolet light to detect the presence of marked flies.

Sticky card data, in a completely randomized design, were analyzed with general linear model procedures, and Tukey's Studentized-range test (SAS Institute 1985) was used for separation of means. Each test constituted a replication, and sample units were the individual sticky cards (216 in Florida and 184 in Maryland). Independent variables included in the model statement were rank, row, card height, time of test (e.g., 


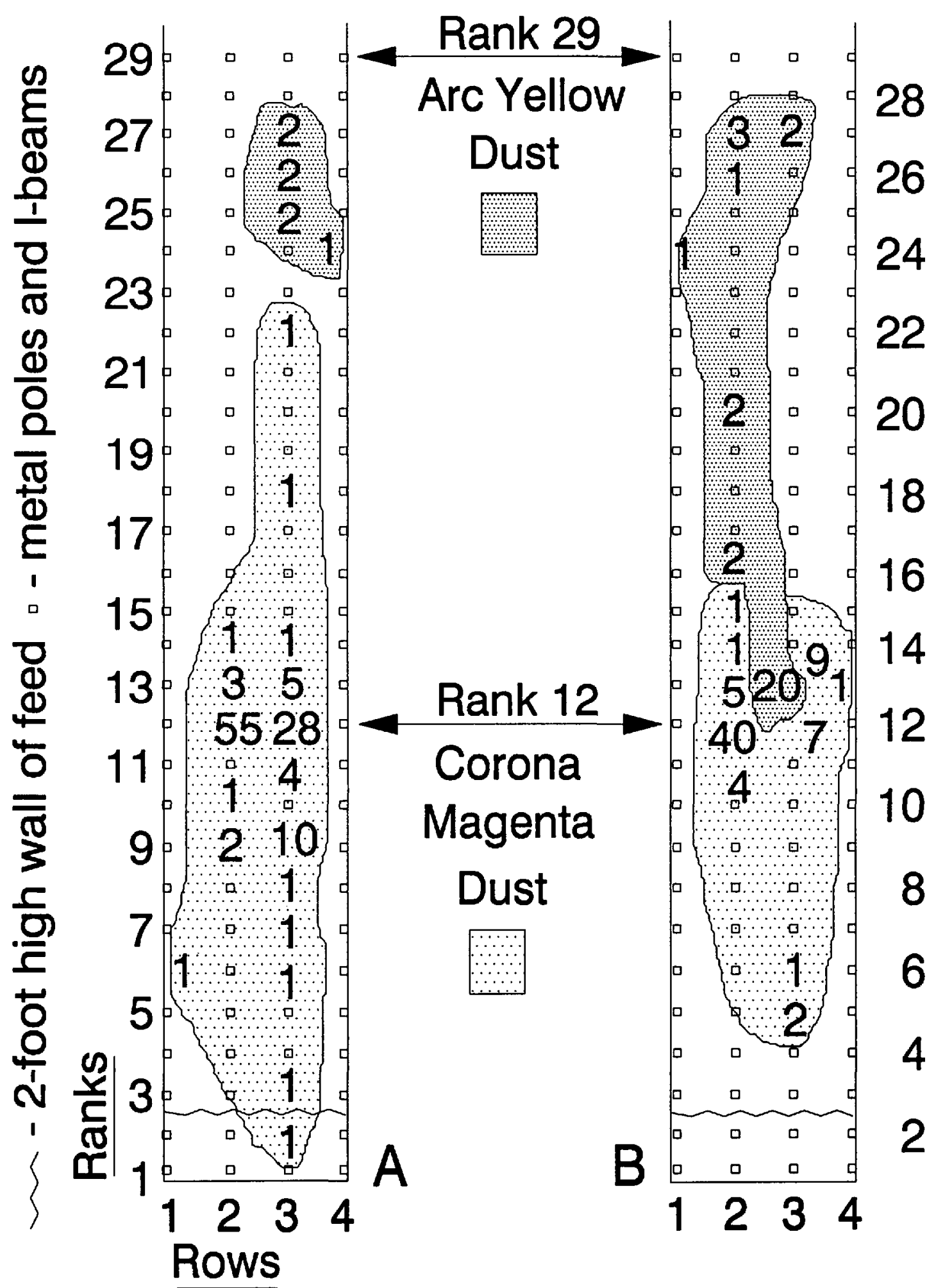

Fig. 1. Floor plan of the portion of the closed, high-rise poultry house used in the Florida studies showing results from the two dispersal studies where fluorescent dust was applied directly onto flies: 5 June (A) and 19 June (B). Numbers in shaded areas represent the marked flies captured on sticky cards at rank-row intersections (height excluded). 
day, night), and test location (e.g., Florida). Sex ratio data (10 replications) were subjected to frequency procedures (SAS Institute 1985) and $\chi^{2}$ analysis (Steel \& Torrie 1980). Ambient temperature and relative humidity, measured during each test at both locations, were uniform throughout the poultry houses and similar in value during each test; these variables had no effect on the analyses and were eliminated from the model statements. Unless otherwise stated, $P=0.05$.

\section{Results and Discussion}

All independent variables (Florida plus Maryland) analyzed in a main effects model were highly significant $(F=51.59$; $d f=33,1,418$; $P<0.0001)$. Numbers of house flies captured on cards in rows $2($ mean $=110)$ and $3($ mean $=100)$ were significantly greater than those captured on cards in rows 1 (mean $=70)$ and $4($ mean $=63$ ) along the exterior walls (Fig. 1). More house flies were captured on cards placed $<0.5 \mathrm{~m}$ above the floor (mean $=99$ ) than on cards at the higher level (mean $=73$ ); as expected, more house flies were captured during the day (mean $=124$ ) than at night (mean $=55$ ). The mean number of house flies captured per card was 94 (range, 0 to 300 ) in Florida and 29 (range, 0 to 168) in Maryland.

Analysis by location revealed that in Maryland, card height had no effect on the number of house flies captured, but in Florida, more $(P<0.05)$ flies were captured on the lower cards. In Maryland, more flies were captured toward the end of the house (e.g., ranks 1, 2,3), but in Florida, more flies were captured toward the interior of the house (e.g., ranks 27, 26). At both locations, significantly greater numbers of house flies were captured on the two interior longitudinal rows (2 and 3) (Fig. 1).

The mean number of Hydrotaea aenescens captured per card was 1.1 (range, 0 to 3 ) in Florida and 2.0 (range, 0 to 6 ) in Maryland. Populations at both locations were very small, but mean differences were significant. Differences in the numbers of $H$. aenescens captured due to rank, row, or card height were not significant.

In Florida, differences between the sex ratios of house flies captured at either card height were not significant $\left(\chi^{2}=0.894, \mathrm{df}=1, P=0.344\right)$. On both top $\left(\chi^{2}=11.96, \mathrm{df}=1, P<0.05\right)$ and bottom $\left(\chi^{2}=5.35, \mathrm{df}=1, P<0.05\right)$ cards, sex ratios were significantly different than 50:50, and females always outnumbered males.

No marked flies were recovered from any sticky card exposed in the tests that ended 23 and 24 May when dusted cards were used. However, numerous marked flies were recovered from the two tests performed in June when flies were dusted directly (Fig. 1). On sticky cards from both of the June tests, flies marked with coronamagenta dust outnumbered flies marked with arc-yellow dust. But, results indicate that a greater number of flies were marked with arcyellow dust than were recovered. Flies were not monitored on rank 29 , where the arc-yellow dust was applied, but the average numbers of flies (marked and unmarked) captured per card on the two closest ranks (i.e., ranks 26 and 27) were 130 and 132 , respectively. The average numbers of flies (marked and unmarked) captured per card on ranks 11,12 , and 13, where the corona-magenta dust was applied, were 84,83 , and 87 , respectively.

The sticky card performed well when used to study the distribution of house fly adults in large, enclosed poultry houses. Cards were easy to use and occupied a small amount of space. Before use, 216 cards (enough for one test in Florida) could be placed in one $16-\mathrm{cm}$ stack. After use, the same number of cards could be placed in four $27-\mathrm{cm}$ stacks. The carrying capacity of the card appeared to be slightly higher than 300 flies. Although the card was designed for short-term use, it could be used for longer periods if $\mathrm{fly}$ populations were small.

Cards must be put out and collected in total darkness to prevent a sampling bias caused when the flies, disturbed by the presence of humans, leave their resting sites and alter their distribution. During the tests that began 1 and 2 May, cards were handled in near, but not complete, darkness, and flies took wing even though it was difficult for us to see. We undoubtedly caused the capture of some of these flies.

In both states, more flies were captured on the two interior rows of support poles rather than along the walls. In contrast, more flies were captured at the lower level near the manure in Florida, but in Maryland, card height made no difference. The Florida data agree with those of Burg \& Axtell (1984), who also captured the most flies in an open-sided, high-rise poultry house at manure level; however, there are no data for houses similar to the ones in our study. Manure was dry enough to cone in Maryland, but liquid in Florida. This factor may have affected the flies' choice of height.

Low-level populations of the facultative larval predator Hydrotaea aenescens were present at both sites. This was surprising in the extremely wet conditions in Florida, although Hydrotaea ignava (Harris) (formerly Ophyra leucostoma) has also been recovered from wet manure in open-sided, high-rise houses (Rutz \& Axtell 1979). It was particularly interesting that the black soldier fly, Hermetia illuscens (L.), which is commonly associated with wet manure conditions, was not present in high numbers, even under Florida conditions. Some larvae were observed in drier areas near mounds of spilled feed, but adults were not seen. We would not expect to recover this fly from the sticky cards. 
The fact that sex ratios were significantly different from 50:50, regardless of height, with females predominating, may indicate a modification of the expected sex stratification behavior observed in outdoor house fly (Black \& Krafsur 1985, Krafsur et al. 1985) and stable fly (Stomoxys calcitrans L.) populations (Hogsette et al. 1989).

When 76 by $127 \mathrm{~mm}$ cards with no adhesive were dusted with fluorescent dust, flies probably contacted the dust only with their feet and removed it by grooming. Therefore, we captured no marked flies with this technique. When dust was applied directly to flies, they were captured with a small number of dust particles remaining on the dorsal aspect of the thorax or on the wing margin. Like stable flies (Hogsette 1983), house flies are apparently unable to groom these areas completely.

The marking studies showed that flies can move up to $29 \mathrm{~m}$ in either direction from the place they were marked (Fig. 1). The maximum dispersal distance was $49.3 \mathrm{~m}$, nearly one-third the length of the house. Flies captured on the same sticky card and marked with fluorescent dust of either color were easily discernible.

Results showed that sticky cards can be used to sample house flies and other fly species in large, closed poultry houses and provide data for distribution, sex class, and in-house dispersal studies. Captured flies could also be subjected to physiological age-grading. For legal purposes, sticky cards could provide a photographic record of flies captured on farms suspected of producing nuisance-level populations.

\section{Acknowledgments}

We thank F. Washington and G. Langley (USDAARS, Gainesville, FL) and L. Shade (USDA-ARS, Beltsville, MD) for their technical assistance in this study.

\section{References Cited}

Axtell, R. C. 1970. Integrated fly-control program for caged-poultry houses. J. Econ. Entomol. 63: $400-405$.

Black, W. C., IV \& E. S. Krafsur. 1985. Use of sticky traps to investigate seasonal trends in spatial distribution of house fies and stable flies (Diptera: Muscidae). J. Med. Entomol. 22: 550-557.

Burg, J. G. \& R. C. Axtell. 1984. Monitoring house fy, Musca domestica (Diptera: Muscidae), populations in caged-layer poultry houses using a baited jug-trap. Environ. Entomol. 13: 1083-1090.
Hogsette, J. A. 1983. An attractant self-marking device for marking field populations of stable flies with fluorescent dusts. J. Econ. Entomol. 76: 510514.

1993. The influence of poultry operations on the urban fly problem in the eastern United States, pp. 17-24. In G. D. Thomas [ed.], Proceedings of the ESA Symposium: Rural Flies in the Urban Environment. NCR-99 and Nebraska Agricultural Experiment Station Publication, University of Nebraska, Lincoln.

Hogsette, J. A., J. P. Ruff \& C. J. Jones. 1989. Dispersal behavior of stable flies (Diptera: Muscidae), pp. 23-32. In J. J. Petersen \& G. L. Greene [eds.], Current status of stable fly (Diptera: Muscidae) research. Misc. Publ. Entomol. Soc. Am. 74.

Krafsur, E. S., W. C. Black IV, C. J. Church \& D. A. Barnes. 1985. Age structure and reproductive biology of a natural house fly (Diptera: Muscidae) population. Environ. Entomol. 14: 159-164.

Lysyk, T. J. \& R. C. Axtell. 1985. Comparison of baited jug-trap and spot cards for sampling house fly, Musca domestica (Diptera: Muscidae), populations in poultry houses. Environ. Entomol. 14: 815819.

Morgan, P. B., D. E. Weidhaas \& R. S. Patterson. 1981. Programmed releases of Spalangia endius and Muscidifurax raptor (Hymenoptera: Pteromalidae) against estimated populations of Musca domestica (Diptera: Muscidae). J. Med. Entomol. 18: 158-166.

Rutz, D. A. \& R. C. Axtell. 1979. Sustained releases of Muscidifurax raptor (Hymenoptera: Pteromalidae) for house fly (Musca domestica) control in two types of caged-layer poultry houses. Environ. Entomol. 8: 1105-1110.

1981. House fly (Musca domestica) control in broiler-breeder poultry houses by pupal parasites (Hymenoptera: Pteromalidae): indigenous parasite species and releases of Muscidifurax raptor. Environ. Entomol. 10: 343-345.

SAS Institute. 1985. SAS user's guide: statistics. SAS Institute, Cary, NC.

Steel, R.G.D. \& J. H. Torrie. 1980. Principles and procedures of statistics: biometrical approach. McGraw-Hill, New York.

Turner, E. C., Jr., \& P. L. Ruszler. 1989. A quick and simple quantitative method to monitor house fy populations in caged layer houses. Poult. Sci. 68 : 833-835.

Wilson, H. R. \& M. S. Mulla. 1975. Spatial and temporal trends of house fly response to an attractive bait on poultry ranches. Environ. Entomol. 4: 395399.

Received for publication 19 May 1992; accepted 10 November 1992. 